\section{Regeneration of commercial nucleic acid extraction columns without the risk of carryover contamination}

\author{
Nagadenahalli B. Siddappa, Appukuttan Avinash, Mohanram \\ Venkatramanan, and Udaykumar Ranga \\ Jawaharlal Nehru Centre for Advanced Scientific Research, Bangalore, India
}

BioTechniques 42:186-192 (February 2007)

doi 10.2144/000112327

Nucleic acid extraction is a basic requirement in a molecular biology laboratory. In terms of purity and yield, commercial nucleic acid extraction columns are superior; however, they are expensive. We report here an efficient strategy to regenerate diverse commercial columns for several rounds without altering the binding capacity of the columns or changing the properties of the nucleic acids purified. Plasmids purified with regenerated columns were functionally identical in super-coiled nature, restriction analysis, expression of the encoded reporter genes, or amplification of the viral RNA in real-time PCR. To ensure that the regenerated columns were free of the residual DNA, we used two different plasmids with different drug-resistance markers. By colony plating and PCR amplification of the encoded genes, we show that the regeneration process is absolute. Using radiolabeled DNA, we demonstrate that DNA exposed to the regeneration reagent is fragmented to molecular weight below 36 bp. Our data collectively prove regeneration of the commercial columns without the concern of carryover contamination. A procedure to permit safe and efficient regeneration of the commercial columns is not only of great advantage to extend the lifetime of these columns but also makes them commercially more affordable, especially in a resource-poor setting.

\section{INTRODUCTION}

Nucleic acid extraction is one of the most basic requirements in a molecular biology laboratory. The diverse nucleic acid extraction protocols by and large fall into one of three categories: $(i)$ the classic extraction methods; (ii) unmodified silica resin-dependent protocols; and (iii) commercial column-based strategies. The classic alkaline lysis method (1) and the phenol chloroform extraction strategy (2) are highly popular, as they are the least expensive and do not require sophisticated equipment. These protocols, however, are associated with serious practical limitations, including the quality of the DNA extracted and the time required for processing a large number of samples. Furthermore, these procedures are not preferred for amplification-based clinical diagnosis, considering the impending risk of contamination $(3,4)$. A wide variety of protocols have been developed using native unmodified silica resin (5-11) or its derivatives, such as diatomaceous earth (12) or pumice (13) for preferential isolation of nucleic acids. Although the quality and quantity of the nucleic acids extracted using the crude silica are superior to the conventional techniques, they are certainly not suitable for a range of applications, such as in vitro transcription/translation, microinjection, and immunization (8). When purity of the nucleic acids is an important consideration, commercial nucleic acid extraction columns have no substitute. A variety of commercial nucleic acid extraction columns available from several vendors by and large use a similar strategy to purify nucleic acids by exploiting the negative charge of the phosphate backbone. Many of the commercial nucleic acid extraction columns are essentially silica-based; however, the silica resin or membranes are chemically modified by attaching strong anionic groups such as the diethylaminoethyl (DEAE) moiety.
The high surface density of the anion groups on such chemically modified silica resins makes the resins efficient and highly selective for nucleic acids in the presence of high salt concentration and $\mathrm{pH}$ conditions. Commercial nucleic acid extraction columns, therefore, ensure the highest level of nucleic acid recovery and purity with little technical complication. Commercial nucleic acid extraction columns, however, are expensive and are disposed of after a single use. Considering the cost factor, we set out to develop a procedure to regenerate the commercial nucleic acid extraction columns. We found that incubation of used commercial nucleic acid extraction columns in $1 \mathrm{M} \mathrm{HCl}$ for $24 \mathrm{~h}$ can efficiently eliminate bound DNA and regenerate them for a fresh round of use. Applying this strategy, the commercial nucleic acid extraction columns can be regenerated many times without a loss in the binding capacity and, importantly, without the possibility of carryover contamination.

\section{MATERIALS AND METHODS}

\section{Regeneration of the Commercial Columns}

Commercial nucleic acid extraction columns after one round of use were stored in $1 \mathrm{M} \mathrm{HCl}$ for a specified period or indefinitely. Before use, the columns were removed from the acid, rinsed thoroughly in sterile distilled water, and equilibrated with Buffer QBT (Qiagen, Valencia, CA, USA) or an equivalent. The volume of water and buffer used to wash the columns typically depended on the nature and the capacity of the columns. For Qiagen-tip 20 columns (Qiagen), for instance, we typically used $5 \mathrm{~mL}$ sterile distilled water per wash for five rounds and $5 \mathrm{~mL}$ Buffer QC (Qiagen) for one round to regenerate the columns.

\section{Transfection of the Mammalian Cells and Reporter Gene Analysis}

HEK 293 cells were transfected with plasmid expression vectors using a standard calcium phosphate method (14). Briefly, cells in 12-well plates 
were transfected with a total of 1.1 $\mu \mathrm{g}$ plasmid DNA, consisting of $1 \mu \mathrm{g}$ reporter vector and $0.1 \mu \mathrm{g}$ pCMV- $\beta$ galactosidase expression vector-the latter included in all the transfections to serve as an internal control for the transfection efficiency. CEM-GFP cells were electroporated using the Gene Pulser ${ }^{\circledR}$ II system (Bio-Rad Laboratories, Hercules, CA, USA) at $240 \mathrm{~V}$ and 950 $\mu \mathrm{F}$ capacitance with a total of $5 \mu \mathrm{g}$ DNA consisting of a mixture of $4 \mu \mathrm{g}$ Tat-expression vector, pCMV Tat, and $1 \mu \mathrm{g}$ cytomegalovirus (CMV)- $\beta$-galactosidase plasmid. Gene expression from the transfected cells was monitored starting from $24 \mathrm{~h}$ after transfection up to $72 \mathrm{~h}$. Quantitation of the reporter genes, including the secreted alkaline phosphatase (SEAP), green fluorescent protein (GFP), $\beta$-galactosidase, and the viral antigen p24 was performed as described previously (15).

\section{Bacterial Transformation and PCR Amplification of the Plasmids}

Two plasmids were used-one encoding the human immunodeficiency virus type-1 (HIV-1) Tat and the ampicillin resistance marker (pCMV-Tat-Amp ${ }^{\mathrm{R}}, 5728 \mathrm{bp}$ ) and the other containing the HIV-1 p24 and the kanamycin resistance marker (pCMVp24-Kan ${ }^{R}, 4759 \mathrm{bp}$ ). Six fresh Qiagentip 20 columns were loaded with pCMV-p24-Kan ${ }^{\mathrm{R}}$, washed, and eluted once with Buffer QF (Qiagen), thus leaving significant quantities of the residual $\mathrm{Kan}^{\mathrm{R}}$ plasmid on the columns. Three of the six columns were incubated in $1 \mathrm{M} \mathrm{HCl}$ for $4 \mathrm{~h}$, while the others were incubated in Buffer QC. After the incubation, both the sets were extensively washed in Buffer QC and loaded with a second plasmid, pCMVTat-Amp ${ }^{R}$. The plasmid was eluted once, and the DNA concentration was determined spectrophotometrically. Chemical competent Escherichia coli cells were transformed with $1 \mathrm{ng}$ plasmid preparations and seeded on LB agar plates supplemented with 50 $\mu \mathrm{g} / \mathrm{mL}$ ampicillin or kanamycin. The number of colonies developed on the plates after a $16 \mathrm{~h}$ incubation at $37^{\circ} \mathrm{C}$ was manually determined. A nested PCR amplification strategy sensitive

A

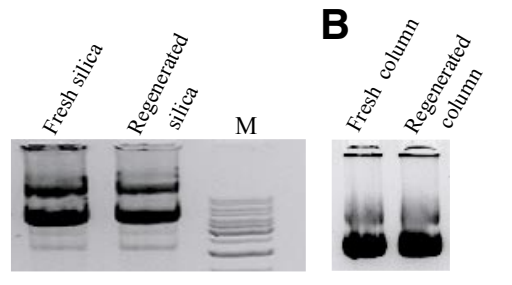

C
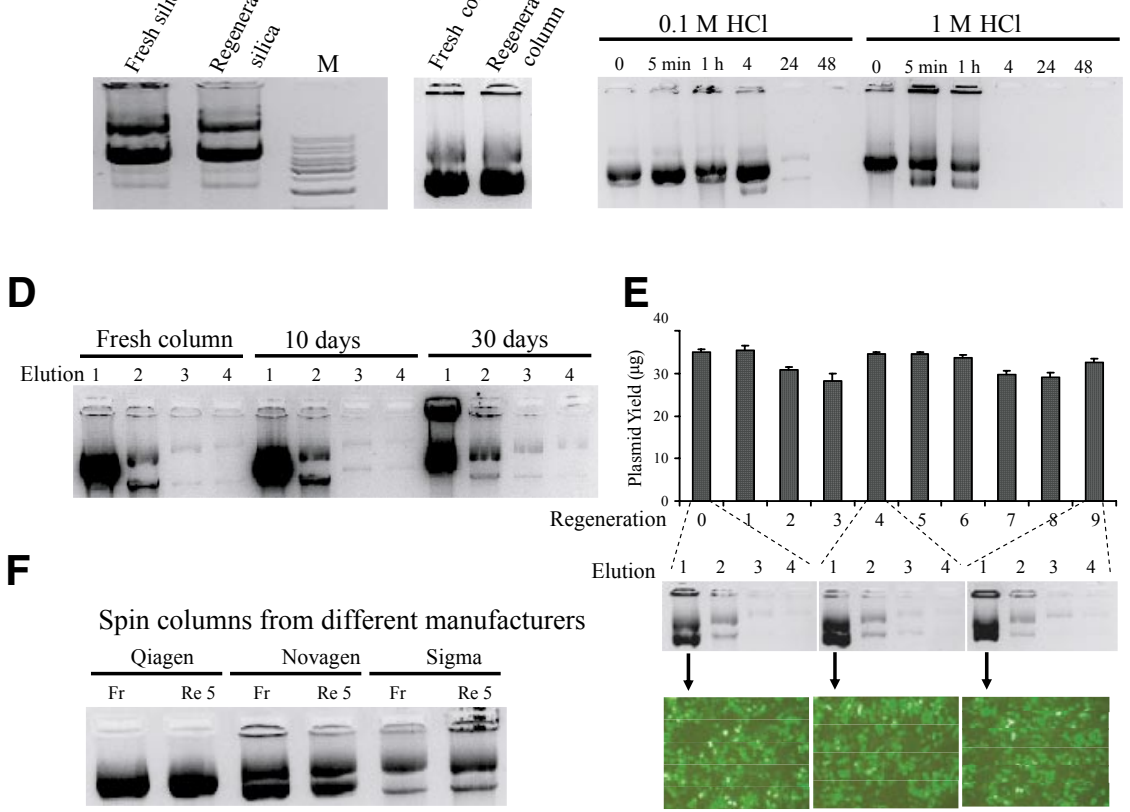

Figure 1. Regeneration of the silica resin and the commercial columns. (A) Comparison of the plasmid DNA extracted using fresh and regenerated silica. M, DNA molecular weight standards (GeneRuler ${ }^{\mathrm{TM}}$ 1-kb DNA ladder; Fermentas, Hanover, MD, USA). (B) Comparison of the plasmid DNA extracted with fresh and regenerated Qiagen-tip 20 columns. Columns after a single use were regenerated and used for the second round of DNA extraction. (C) Determination of the strength of the acid required for column regeneration. Qiagen-tip 20 columns were loaded with pCMV-EGFP, incubated for different periods in 0.1 or $1 \mathrm{M} \mathrm{HCl}$, washed with Buffer QC, and then bound DNA was eluted and visualized on an agarose gel. (D) Prolonged exposure of the columns to $1 \mathrm{M} \mathrm{HCl}$ does not alter DNA binding capacity. Fresh columns were incubated in $1 \mathrm{M} \mathrm{HCl}$ continuously for specified periods and used for plasmid isolation. DNA from each of the columns was eluted for four successive rounds to identify minor differences in the column binding capacity. (E) Plasmid yield from columns regenerated for several rounds. A set of three Qiagen-tip 20 columns was subjected to nine successive rounds of regeneration with $1 \mathrm{M}$ $\mathrm{HCl}$. Plasmid DNA, pCMV-EGFP, was extracted from the same stock of the harvested bacteria frozen in multiple aliquots. The plasmid yield is presented as the mean of three replicate values $\pm 1 \mathrm{sD}$. Expression of the encoded enhanced green fluorescent protein (EGFP) in HEK 293 cells $48 \mathrm{~h}$ after transfection was documented at $20 \times$ resolution using a DFC320 digital camera (Leica, Heerbrugg, Germany) attached to a UV fluorescent microscope (Leica). Data for only three plasmid extractions are presented (rounds 0,4 , and 9). (F) Spin columns from three different manufacturers, Qiagen (QIAprep ${ }^{\circledR}$ Spin Miniprep kit), Novagen (Madison, WI, USA; Spinprep ${ }^{\mathrm{TM}}$ Plasmid kit), and Sigma-Aldrich (St. Louis, MO, USA; GenElute TM Plasmid Miniprep kit), were tested in parallel using fresh columns (Fr) or columns regenerated for five rounds $(\operatorname{Re} 5)$. All the above experiments were repeated two or three times, and the data are from representative experiments.

enough to detect single-copy template DNA (see Figure 3B) was used to detect Tat or $\mathrm{p} 24$ encoded by the Amp ${ }^{\mathrm{R}}$ and $\mathrm{Kan}^{\mathrm{R}}$ plasmids, respectively. Plasmid preparations extracted above were diluted in $50 \mathrm{ng} / \mu \mathrm{L}$ salmon sperm DNA as carrier DNA, to contain 10,000 or 1000 input copies for the PCR. For positive standards, pCMV-Tat-Amp ${ }^{R}$ and $\mathrm{pCMV}-\mathrm{p} 24-\mathrm{Kan}^{\mathrm{R}}$ plasmids were subjected to a serial 10-fold dilution in carrier DNA. The amplified fragments were resolved on a $1 \%$ agarose gel and visualized by ethidium bromide staining.

\section{Real-Time Reverse Transcription PCR for the HIV-1 Long Terminal Repeat}

Total RNA was extracted from 150 $\mu \mathrm{L}$ HIV-1 seropositive plasma samples using two different commercial kits, Auprep ${ }^{\circledR}$ PCR Purification columns (Life Technologies ${ }^{\mathrm{TM}}$; Invitrogen, Carlsbad, CA, USA) and Qiagen Viral RNA Mini kit columns, following the manufacturers' instructions. RNA bound to the columns was eluted in $50 \mu \mathrm{L}$ RNasefree water, and half of this quantity was used in reverse transcription reaction 
A

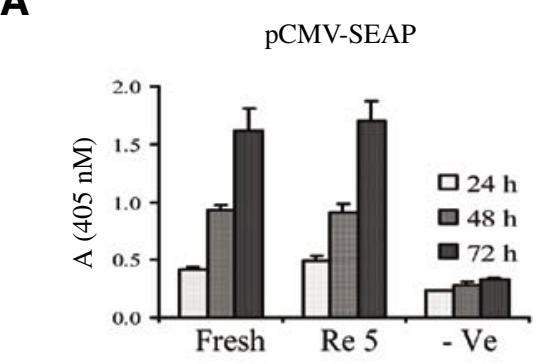

D

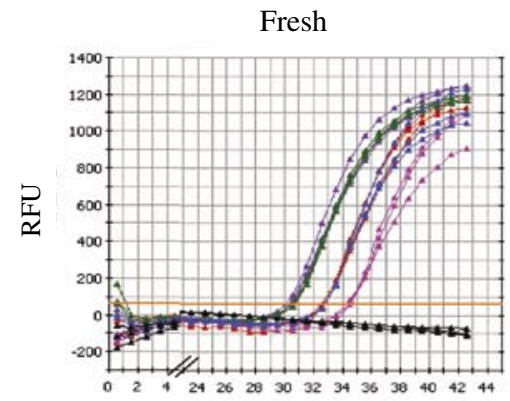

B

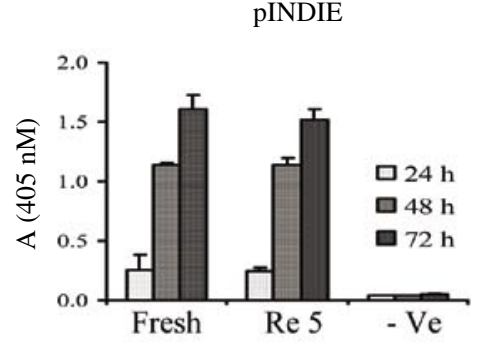

Re 1
C

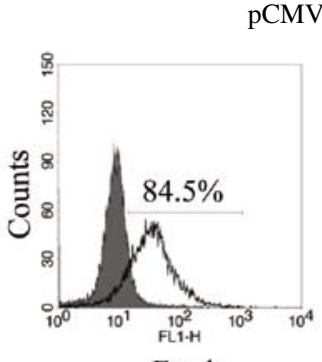

Fresh

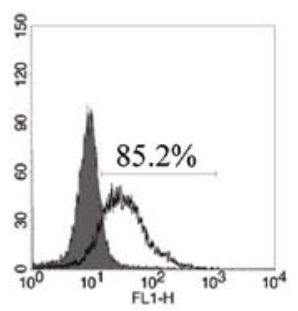

$\operatorname{Re} 5$

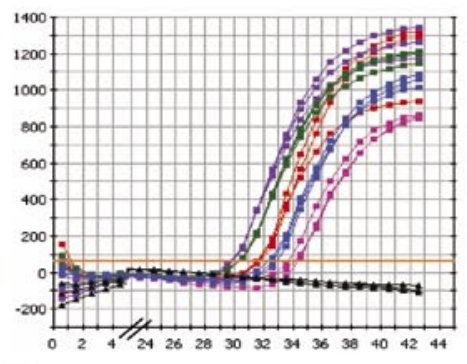

\begin{tabular}{|lcc|}
\hline \multirow{2}{*}{ Donor } & \multicolumn{2}{c|}{$\mathbf{C}_{\mathbf{T}}$ Value } \\
\cline { 2 - 3 } & Fresh & Regenerated \\
\hline P1 & $32.7,32.7,32.7$ & $31.5,31.7,31.6$ \\
P2 & $34.3,34.6,34.6$ & $34.1,34.4,33.7$ \\
P3 & $30.3,30.2,30.0$ & $29.8,29.8,29.6$ \\
P4 & $30.6,30.5,30.6$ & $30.3,30.3,30.3$ \\
P5 & $32.7,32.7,32.7$ & $32.6,32.8,32.3$ \\
\hline
\end{tabular}

Cycle

Figure 2. Functional characterization of different plasmids extracted using regenerated columns. (A) Mammalian expression of alkaline phosphatase. HEK 293 cells were transiently transfected with pCMV-SEAP, and the levels of the alkaline phosphatase present in the spent media at three different time points were determined. - Ve, cells transfected with an empty vector. (B) Virion production from mammalian cells. HEK 293 cells were transiently transfected with pINDIE, a reference human immunodeficiency virus type 1 (HIV-1) subtype $\mathrm{C}$ molecular clone, and the amount of viral p24 antigen released into the culture medium was quantified at three different time points using a commercial kit. (C) Tat transactivation assay. CEM-GFP cells, containing a reporter green fluorescent protein (GFP) under the control of HIV-1 long terminal repeat (LTR), were electroporated with pCMV-Tat encoding the viral transactivator protein. Cells were fixed 72 $\mathrm{h}$ after transfection, and the expression of GFP was determined by flow cytometry (BD FACSCalibur ${ }^{\mathrm{TM}}$; BD Biosciences, San Jose, CA, USA). The percentages of cells positive for GFP expression are indicated. All the above experiments were repeated twice, and the data presented are from representative experiments. (D) Evaluation of the column-extracted viral RNA in a real-time reverse transcription PCR (RT-PCR). Total RNA was extracted from the plasma samples of five drug-naïve HIV-1 seropositive donors (color-coded) using Qiagen columns, each in triplicate. The cycle threshold $\left(\mathrm{C}_{\mathrm{T}}\right)$ values have been illustrated in the table. The experiment was performed two times, and the data are from one representative experiment. Essentially identical results were obtained with RNA extraction columns from a different vendor (Auprep; Life Technologies, Invitrogen; data not presented). RFU, relative fluorescence units; A, absorbance.

performed using a High-Capacity cDNA Archive kit (Applied Biosystems, Foster City, CA, USA). The reaction volume of $50 \mu \mathrm{L}$ contained $25 \mu \mathrm{L}$ extracted RNA, $500 \mathrm{ng} / \mathrm{mL}$ random hexamers, $125 \mathrm{U}$ SuperScript ${ }^{\circledR}$ Reverse Transcriptase (Invitrogen), $2 \mu \mathrm{L} 25 \times \mathrm{dNTP}$ mix, 5 $\mu \mathrm{L} 10 \times$ reverse transcription buffer, and $1 \mu \mathrm{L}$ RNase inhibitor. After denaturation of the RNA for $5 \mathrm{~min}$ at $95^{\circ} \mathrm{C}$, cDNA was synthesized at $37^{\circ} \mathrm{C}$ for $2 \mathrm{~h}$. TaqMan ${ }^{\circledR}$ PCR was performed using 5 $\mu \mathrm{L}$ reverse transcription mix as template and a primer pair targeting a 133-bp sequence in the HIV-1 subtype-C long terminal repeat (LTR). A TaqMan probe covalently attached to CyTM 5 at the $5^{\prime}$ end and BHQ3 at the $3^{\prime}$ end was used for the detection. The reverse transcription PCR (RT-PCR) was performed on an iCycler ${ }^{\mathrm{TM}}$ real-time thermal cycler (Bio-Rad Laboratories), and the cycle threshold $\left(\mathrm{C}_{\mathrm{T}}\right)$ values were calculated using iCycler IQ software (Bio-Rad Laboratories).

\section{Analysis of the Fate of the DNA Exposed to Acid}

A plasmid pC-LTR-SIE was linearized and labeled with $[\alpha-$ $\left.{ }^{32} \mathrm{P}\right] \mathrm{dCTP}$ in a standard random labeling reaction using the NEBlot ${ }^{\circledR}$ kit (New England BioLabs, Ipswich, MA, USA) and purified on a G-50 Sephadex ${ }^{\circledR}$ column. Labeled DNA was mixed with the same but unlabeled plasmid DNA at a 1:50 ratio for the assay. Six fresh spin columns were loaded each with $10 \mu \mathrm{g}$ pulsed DNA and exposed to 200 $\mu \mathrm{L} 1 \mathrm{M} \mathrm{HCl}$ in a plastic vial in a way that the membrane is immersed in the acid. The column-bound DNA was treated for different periods ranging from $0 \mathrm{~min}$ to $24 \mathrm{~h}$. At the end of the incubation, equal volume of $1 \mathrm{M}$ Tris buffer, $\mathrm{pH}$ 11.5, was added to each column, mixed well, and the column was spun at full speed to collect the sample in the lower chamber. DNA was eluted from the columns and precipi- tated overnight at $-20^{\circ} \mathrm{C}$ by adding 2 volumes of ethanol in the presence of $2 \mathrm{M}$ ammonium acetate, $\mathrm{pH}$ 4.8. DNA pellet was dissolved in $50 \mu \mathrm{L}$ Tris EDTA (TE), $\mathrm{pH} 8.0$, normalized for the radioactivity counts, and resolved on a gradient polyacrylamide gel $(6 \%$ $15 \%)$. The gel was wrapped in a plastic film, directly exposed to a phosphor imager plate, and analyzed on an FLA5000 Phosphor Imager (Fuji, Osaka, Japan).

\section{RESULTS AND DISCUSSION}

\section{Regeneration of the Commercial Columns}

Previously we reported a strategy for small-scale plasmid DNA extraction using silica (8). Preparation of the silica required incubation of the resin at a low $\mathrm{pH}$ to destroy resin-associated DNA. To see if silica used once can be 
regenerated, we incubated used resin in $1 \mathrm{M} \mathrm{HCl}$ for $4 \mathrm{~h}$ and compared it with fresh resin for the extraction of plasmid DNA. Fresh and treated silica both isolated plasmid DNA at comparable levels (Figure 1A), suggesting that the DNA binding property of the resin was not acid-labile. We next extended this regeneration technique to Qiagen-tip 20 columns and identified that these columns could be regenerated in the same manner (Figure 1B). Following this observation, we set up several experiments to optimize regeneration of the commercial nucleic acid extraction columns from different suppliers. For consistency, bacterial cultures containing plasmid vectors were grown to large volumes, the cells were harvested, resuspended in Buffer P1 (Qiagen), and then stored in multiple aliquots in a deep freezer. Aliquots were removed as required and used for various experiments described below.

To identify the optimal concentration of $\mathrm{HCl}$ and the time of incubation needed to regenerate the columns, we loaded several fresh columns with plasmid DNA. Columns with DNA bound on them were incubated in 0.1 or $1.0 \mathrm{M} \mathrm{HCl}$ for different periods; the bound DNA was eluted with Buffer $\mathrm{QF}$, and the DNA was resolved on a $1 \%$ agarose gel. Incubation of the columns in $0.1 \mathrm{M} \mathrm{HCl}$ required 48 $\mathrm{h}$ to completely eliminate the bound plasmid DNA from the columns, whereas no plasmid DNA was found on the columns after $4 \mathrm{~h}$ incubation in $1 \mathrm{M}$ $\mathrm{HCl}$ (Figure 1C). Prolonged exposure of the columns to $1 \mathrm{M} \mathrm{HCl}$ for 0,10 , and 30 days or longer did not alter the DNA binding capacity of the columns, suggesting that the active groups on the resin surface are quite stable to acid exposure (Figure 1D). As illustrated, the columns can be regenerated many times without a reduction in the binding capacity (Figure 1E). In our experience, most of the columns could be regenerated up to 20 times. DNA eluted from each round was resolved on a $1 \%$ agarose gel to confirm the supercoiled nature of the plasmid (Figure 1E, middle panel) and comparable expression levels of the encoded enhanced GFP (EGFP) (Figure 1E, bottom panel). We applied the regener-
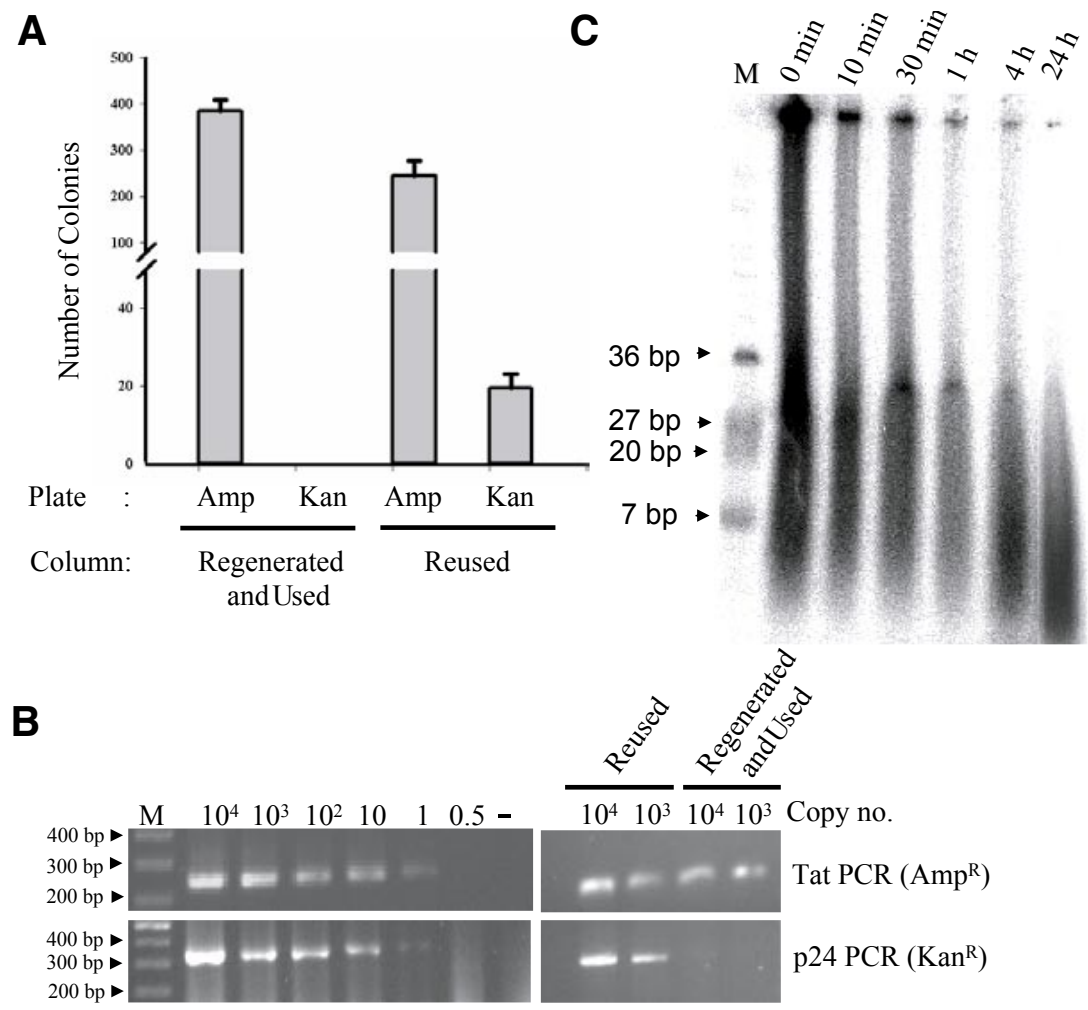

Figure 3. Regenerated columns do not carry over DNA to subsequent cycles of purification. (A) Regeneration process destroys the residual DNA. Two sets of columns were differentially treated to leave the contaminating plasmid (pCMV-p24-Kan ${ }^{\mathrm{R}}$ ) on one of the sets. A second plasmid (pCMV-Tat$A m p^{R}$ ) was extracted using both the sets, and transformed bacteria were seeded on LB agar plates supplemented with ampicillin or kanamycin. The number of colonies developed on the plates was manually determined. This experiment was repeated three times, and the data presented are from one representative experiment. The data are presented as mean of triplicate assays \pm 1 SD (B) PCR-mediated detection of the contaminating plasmid DNA. Plasmid preparations extracted above were diluted to defined copy numbers in the presence of carrier DNA and used as a template in a nested PCR for the detection of Tat and p24 targets encoded by the $\mathrm{Amp}^{\mathrm{R}}$ and $\mathrm{Kan}^{\mathrm{R}}$ plasmids, respectively (right panels). For positive standards, the plasmids were subjected to a serial 10-fold dilution in the presence of carrier DNA to contain defined number of copies as shown (left panels). M, DNA molecular weight standards (GeneRuler 100-bp DNA ladder; Fermentas), and the standard sizes are indicated. (C) Acid-treated DNA is degraded on the column to low molecular weight fragments. Isotopically labeled plasmid DNA was loaded to the columns and exposed to $1 \mathrm{M} \mathrm{HCl}$ for different periods as shown. Eluted DNA normalized for the radioactivity counts was subjected to electrophoresis on a $6 \%-15 \%$ gradient polyacrylamide gel and analyzed by phosphor imager scanning. The experiment was repeated several times, and the data presented are representative of one such experiment. Oligonucleotides of known molecular size were end-labeled with $\left[\gamma^{-32} \mathrm{P}\right] \mathrm{dATP}$ and used as molecular weight standards as shown.

ation protocol to diverse columns from Qiagen that use different strategies of plasmid purification, spin versus gravity separation, or different scales of DNA yield (data not presented), as well as columns from different manufacturers (Figure 1F). Additionally, we tested columns intended for genomic DNA isolation (data not presented), extraction of DNA from agarose gels (data not presented), and RNA extraction (see section entitled Nucleic Acids Purified with Regenerated Columns Are Functionally Competent) and obtained similar results.

\section{Nucleic Acids Purified with Regenerated Columns Are Functionally Competent}

We observed comparable expression levels of different mammalian genes from plasmids prepared using fresh columns or columns regenerated for five rounds (Figure 2). A plasmid vector pCMV-SEAP, encoding SEAP under the control of a CMV promoter, expressed comparable levels of SEAP when the plasmid was isolated with fresh or regenerated columns (Figure 2A). Identical results were obtained 


\section{Short Technical Reports}

with a GFP expression vector, pCMVEGFP (Figure 1E, bottom panel). The plasmid pINDIE harbors a full-length molecular clone of HIV-1. HEK 293 cells transfected with pINDIE secreted comparable levels of the viral core antigen p24 into the medium at 24, 48, and $72 \mathrm{~h}$ (Figure 2B). CEM-GFP cells electroporated with pCMV-Tat, prepared using fresh and regenerated columns, induced comparable levels of GFP expression as determined by flow cytometry (Figure 2C).

We also regenerated commercial nucleic acid extraction columns for total RNA extraction from human plasma samples and evaluated the RNA quality in a real-time RT-PCR targeting the HIV-1 promoter sequence. Total RNA was extracted from $150-\mu \mathrm{L}$ plasma of each of five individual HIV-1 seropositive donors using commercial nucleic acid extraction columns supplied by two different manufacturers. RNA extracted with fresh or regenerated columns amplified the target sequence in a manner indistinguishable from each other (Figure 2D). We did not see large differences in viral titers among the individual donors tested, probably as all the donors were drug-naïve and asymptomatic. However, the $\mathrm{C}_{\mathrm{T}}$ values of the samples of the highest and lowest titer differed by 4.5 cycles, suggesting a 20 - to 25 -fold difference in viral load between these donors.

\section{Acid-Treated DNA Is Degraded to Small Fragments and Cannot Function as a Template}

The most serious concern with the reuse of the disposable columns is the possibility of nucleic acid carryover from one preparation to the next. Even the minutest quantity of nucleic acid carryover between samples could have serious consequences for subsequent molecular manipulations. Therefore, it is critical to ensure that the columns are absolutely free of residual DNA after regeneration. We devised a series of experiments to detect residual DNA on the columns after regeneration. We selected a pair of vectors containing two different drug markers, ampicillin and kanamycin, for differential colony plating and two different gene sequences, p24 and Tat, for differential
PCR amplification in the subsequent experiments.

Six fresh Qiagen-tip 20 columns were loaded with a plasmid DNA containing the kanamycin-resistance gene (pCMV$\left.\mathrm{p} 24-\mathrm{Kan}^{\mathrm{R}}\right)$. After washing, the columns were eluted only once, thus leaving a significant quantity of the residual $\mathrm{Kan}^{\mathrm{R}}$ plasmid on the columns, which was expected to be approximately $5-6 \mu \mathrm{g}$ or $20 \%$ of the overall binding capacity of the column (see Figure 1D). Three of the six columns were incubated in $1 \mathrm{M} \mathrm{HCl}$ for $4 \mathrm{~h}$ to strip the residual DNA. The other three columns were incubated in Buffer QC and were expected to contain residual plasmid DNA that should be carried over to the next round of purification. After the incubation, both sets of the columns were washed and loaded with a second plasmid containing the ampicillin-resistance gene (pCMVTat-Amp ${ }^{\mathrm{R}}$ ). Bound plasmid was eluted from the columns, and competent $E$. coli cells were transformed and seeded on agarose plates supplemented with ampicillin or kanamycin. The number of colonies developed on the plates after a $16 \mathrm{~h}$ incubation was determined. Amp ${ }^{\mathrm{R}}$ plasmid extracted using the regenerated column contained approximately 400 colonies on the ampicillin plate and absolutely no colonies on the kanamycin plate (Figure 3A). In contrast, plasmid DNA extracted using the contaminated columns contained approximately 300 and 20 colonies on plates supplemented with ampicillin and kanamycin, respectively. To validate this finding, we used PCR to detect the presence of residual DNA in the plasmid preparation. We optimized PCRs for Tat (Amp ${ }^{\mathrm{R}}, 240 \mathrm{bp}$ ) and p24 (Kan $\left.{ }^{\mathrm{R}}, 330 \mathrm{bp}\right)$ to detect target genes on respective plasmids. Both the PCRs were sensitive enough to detect a single copy of the template (Figure 3B, left panels). The Tat PCR successfully amplified the target DNA from both the plasmid preparations as expected (Figure 3B, top panel). In contrast, p24 PCR-amplified only the DNA isolated with the reused, but not the regenerated columns (Figure 3B, lower panel). Furthermore, we examined the fate of the DNA exposed to $1 \mathrm{M} \mathrm{HCl}$ while bound on the column. Radioactively labeled DNA bound on the columns was exposed to $1 \mathrm{M} \mathrm{HCl}$ for different time periods, recovered, and analyzed as described in the Materials and Methods section. We observed a progressive degradation of the DNA with prolonged exposure to $\mathrm{HCl}$ (Figure 3C). At zero time point, most of the DNA remained in the well, and DNA that entered the gel developed a smear in the lane. DNA exposed to acid for periods as short as 60 min readily entered the gel and migrated below the 36-bp marker. After $24 \mathrm{~h}$, nearly all the DNA moved into the gel and was predominantly reduced to a size below $36 \mathrm{bp}$. The data presented in Figure 3 collectively proved that DNA exposed to $1 \mathrm{M} \mathrm{HCl}$ was efficiently destroyed, and the columns regenerated thus were safe for reuse without a risk of carryover contamination.

In summary, we identified an efficient, simple, and inexpensive procedure to regenerate commercial nucleic acid extraction columns. Commercial kits supply limited volume of the buffers required for column regeneration. However, the composition of the buffers is provided in several technical brochures, and a laboratory with adequate molecular biology expertise should be able to make its own reagents. We routinely store the columns in $1 \mathrm{M} \mathrm{HCl}$, as this procedure not only regenerates the columns but also prevents microbial growth. A procedure to permit safe and efficient regeneration of the commercial columns makes them commercially more affordable, especially in a resource-poor setting.

\section{ACKNOWLEDGMENTS}

A number of reagents used in this study were obtained through the AIDS Research and Reference Reagent Program, Division of Acquired Immunodeficiency Syndrome (AIDS), National Institute of Allergy and Infectious Diseases (NIAID), and National Institutes of Health (NIH), USA. U.R. acknowledges financial support from The Department of Science and Technology, government of India (grant no. VII-PRDSF/105/0506/TDT). N.B.S. is a recipient of the Council for Scientific and Industrial Research (CSIR) fellowship from the government of India. 


\section{Short Technical Reports}

\section{COMPETING INTERESTS STATEMENT}

The authors declare no competing interests.

\section{REFERENCES}

1. Birnboim, H.C. and J. Doly. 1979. A rapid alkaline extraction procedure for screening recombinant plasmid DNA. Nucleic Acids Res. 7:1513-1523.

2.Sambrook, J. and D.W. Russel. 2001. Molecular Cloning: A Laboratory Manual. CSH Laboratory Press, Cold Spring Harbor, NY.

3. Burkardt, H.J. 2000. Standardization and quality control of PCR analyses. Clin. Chem. Lab. Med. 38:87-91.

4. Kwok, S. and R. Higuchi. 1989. Avoiding false positives with PCR. Nature 339:237238.

5.Boom, R., C.J.A. Sol, M.M.M. Salimans, C.L. Jansen, P.M.E.W. Dillen, and J. van der Noordaa. 1990. Rapid and simple method for purification of nucleic acids. J. Clin. Microbiol. 28:495-503.

6. Vogelstein, B. and D. Gillespie. 1979. Preparative and analytical purification of DNA from agarose. Proc. Natl. Acad. Sci. USA 76:615-619.

7. Boyle, J.S. and A.M. Lew. 1995. An inexpensive alternative to glassmilk for DNA purification. Trends Genet. 11:8.

8. Lakshmi, R., V. Baskar, and U. Ranga. 1999. Extraction of superior-quality plasmid DNA by a combination of modified alkaline lysis and silica matrix. Anal. Biochem. 272:109-112

9. Marko, M.A., R. Chipperfield, and H.C. Birnboim. 1982. A procedure for the largescale isolation of highly purified plasmid DNA using alkaline extraction and binding to glass powder. Anal. Biochem. 121:382-387.

10. Neudecker, F. and S. Grimm. 2000. Highthroughput method for isolating plasmid DNA with reduced lipopolysaccharide content. BioTechniques 28:107-109.

11. Carter, M.J. and I.D. Milton. 1993. An inexpensive and simple method for DNA purifications an silica particles. Nucleic Acids Res. 21:1044.

12. Michael, L.C., inventor; Bio-Rad Laboratories, asignee. Process for the purification of DNA on diatomaceous earth. U.S. patent 5075430. 1991.

13. Heyd, M.L. and J.D. Diehl, Jr. 1996. Recovering DNA from agarose gels with pumice. BioTechniques 20:394-398.

14. Chen, C. and H. Okayama. 1987. High-efficiency transformation of mammalian cells by plasmid DNA. Mol. Cell. Biol. 7:2745-2752.

15.Siddappa, N.B., M. Venkatramanan, P. Venkatesh, M.V. Janki, N. Jayasuryan, A. Desai, V. Ravi, and U. Ranga. 2006. Transactivation and signaling functions of Tat are not correlated: biological and immunological characterization of HIV-1 subtype-C Tat protein. Retrovirology 3:53.
Received 16 July 2006; accepted 15 October 2006.

Address correspondence to Udaykumar Ranga, Molecular Virology Laboratory, Molecular Biology and Genetics Unit, Jawaharlal Nehru Centre for Advanced Scientific Research, Jakkur (P.O.), Bangalore 560 064, India. e-mail: udaykumar@jncasr.ac.in

To purchase reprints of this article, contact: Reprints@BioTechniques.com 